\title{
Chondrogenic Differentiation in vitro of Murine Two-Factor Induced Pluripotent Stem Cells is Comparable to Murine Embryonic Stem Cells
}

\author{
Sina Kuboth Jan Kramer Jürgen Rohwedel \\ Department of Virology and Cell Biology, University of Lübeck, Lübeck, Germany
}

\section{Key Words}

Chondrogenesis $\cdot$ In vitro differentiation $\cdot$ Murine induced pluripotent stem cells $\cdot$ Murine embryonic stem cells

\begin{abstract}
Differentiation of embryonic stem (ES) cells via embryoid bodies has been established as an appropriate model to study the development of various cell types in vitro. Here, we show that murine induced pluripotent stem (iPS) cells, reprogrammed by exogenous expression of the two transcription factors Oct4 and KIf4 (2F OK iPS), differentiate into chondrocytes in vitro characterized by the appearance of Alcian blue-stained nodules and the expression of cartilage-associated genes and proteins. Quantitatively, the chondrogenic differentiation potential of $2 \mathrm{~F}$ OK iPS and ES cells was found to be similar. Further, we demonstrate the induction of chondrogenic iPS cell differentiation by certain members of the transforming growth factor- $\beta$ family (BMP-2, TGF- $\beta_{1}$ ). The number of Alcian blue-positive nodules and the expression of the cartilage marker molecule collagen type II increased after application of BMP-2, whereas simultaneous treatment with both BMP-2 and TGF- $\beta_{1}$ showed no significant effect on gene expression.

Copyright $\odot 2012$ S. Karger AG, Basel
\end{abstract}

\section{Introduction}

In vitro differentiation of murine embryonic stem (ES) cells via embryoid bodies (EBs) was established as a suitable model system to study cartilage differentiation in vitro, recapitulating chondrogenesis from the undifferentiated stem cell via mesenchymal and chondrogenic progenitors up to mature chondrocytes [Kramer et al., 2000; Hegert et al., 2002; Kramer et al., 2005a, b]. ES cells have the potential to develop into cells of all three primary germ layers due to their origin from the inner cell mass of early embryos [Evans and Kaufman, 1981]. However, the use of human ES cells is limited because of ethical issues related to the destruction of human embryos or oocytes. An alternative approach is offered by induced pluripotent stem (iPS) cells.

\section{Abbreviations used in this paper}

2F two-factor

BSA bovine serum albumin

DMEM Dulbecco's modified Eagle's medium

EBs

ES

iPS

MEF embryoid bodies

embryonic stem

induced pluripotent stem

mouse embryonic fibroblasts

\section{KARGER}

Fax +4161306 1234

E-Mail karger@karger.ch

www.karger.com
(C) 2012 S. Karger AG, Basel

$1422-6405 / 12 / 1966-0481 \$ 38.00 / 0$

Accessible online at:

www.karger.com/cto
Prof. Dr. Jürgen Rohwedel

Department of Virology and Cell Biology, University of Lübeck Ratzeburger Allee 160

DE-23538 Lübeck (Germany)

Tel. +49 451500 4095, E-Mail rohwedel@ molbio.uni-luebeck.de 
The first reported generation of iPS cells from murine fibroblasts by retroviral transduction of a defined set of transcription factors [Takahashi and Yamanaka, 2006] was followed by the development of various new strategies to improve and refine the reprogramming technique, such as the use of different cell types to be reprogrammed, variations of the reprogramming factors, and nonintegrating delivery methods [Maherali and Hochedlinger, 2008]. The generated iPS cells were similar to ES cells in terms of their morphology, growth properties, and gene expression profile [Wernig et al., 2007]. Further, iPS cells were shown to be competent for germline transmission [Okita et al., 2007] and capable of forming viable adult chimaeras [Kang et al., 2009]. In an approach to minimize the number of factors necessary for reprogramming, it was shown that Oct4 together with Klf4 is sufficient to reprogram neural stem cells into pluripotent stem cells, so-called two-factor (2F) OK iPS cells [Kim et al., 2008]. Despite many technical advances in the derivation of iPS cells, the question of whether iPS cells show differentiation efficiencies in vitro fully equivalent to that of ES cells remains to be answered.

The iPS cell system has already been used to study the differentiation of numerous cell types such as cardiovascular, hematopoietic, and neuronal cells in vitro. However, the question of whether $2 \mathrm{~F}$ iPS cells can be differentiated into chondrocytes and actually represent an equivalent alternative to ES cells regarding their use as an in vitro model system of chondrogenesis remains to be elucidated.

Here, we demonstrate that murine $2 \mathrm{~F}$ OK iPS cells [Kim et al., 2008] spontaneously differentiate into chondrogenic cells in vitro evidenced by the appearance of cartilage nodules and the expression of cartilage-associated genes and proteins with an efficiency comparable to that of murine ES cells. Moreover, we show that members of the transforming growth factor- $\beta$ (TGF- $\beta$ ) family enhance $2 \mathrm{~F}$ OK iPS cell-derived chondrogenic differentiation.

\section{Material and Methods}

Cell Culture and Differentiation of EBs

Murine iPS cells of line 2F OK, clone F-4 (2F OK iPS) [Kim et al., 2008], and ES cells of line D3 (ES1) [Doetschman et al., 1985] were cultivated on a feeder layer of mitomycin C-inactivated mouse embryonic fibroblasts (MEF) in cultivation medium consisting of Dulbecco's modified Eagle's medium (DMEM; Invitrogen, Karlsruhe, Germany) supplemented with $15 \%$ heat inactivated fetal calf serum (FCS; Thermo Scientific, Karlsruhe, Germany), 2 mM L-glutamine (Invitrogen, Karlsruhe, Germany), $5 \times$ $10^{-5}$ M $\beta$-mercaptoethanol (Sigma-Aldrich, St. Louis, Mo., USA), nonessential amino acids (Invitrogen), and penicillin/streptomy- cin (PAA; Pasching, Austria) as described previously [Wobus et al., 1988, 1991]. In addition, as a further control, the murine ES cell line EB5 NERT (ES2) [Schroeder et al., 2006], was cultivated to obtain RNA for the study of pluripotency marker expression.

For differentiation, aliquots of $20 \mu \mathrm{l}$ differentiation medium (with $20 \%$ inactivated FCS instead of $15 \%$ ) containing 800 cells were cultivated in 'hanging drops' for 2 days and subsequently in suspension in bacteriological petri dishes for an additional 3 days as described previously [Rohwedel et al., 1994]. The 5-day-old EBs were plated onto gelatin- $(0.1 \%)$ coated 24 -well plates for Alcian blue staining, onto 6-cm tissue culture plates for total RNA isolation, and onto 2-well chamber slides for histochemical and immunostaining and cultivation was continued in cultivation medium with $0.2 \%$ FCS. Alcian blue staining was performed as described previously [Kramer et al., 2000]. EBs were stained with Alcian blue at different times and the number of stained nodules in individual EBs was counted. To study growth factor-induced modulation of iPS and ES cell-derived chondrogenesis, BMP-2 (10 $\mathrm{ng} / \mathrm{ml})$ (Invitrogen) and the combination of BMP-2 (10 ng/ml) and TGF- $\beta_{1}(2 \mathrm{ng} / \mathrm{ml})$ (PeproTech, Hamburg, Germany) were added to the differentiation medium during the suspension phase (2-5 days) of EB development and differentiation was compared to control cultures without growth factors. The concentrations of the growth factors used have been shown to be sufficient to induce chondrogenic differentiation in the ES cell system [Kramer et al., 2000; zur Nieden et al., 2005].

Experiments were done at least in triplicate and data analysis was performed using Sigma Plot 11.0 software (Jandel, Corte Madeira, Calif., USA). For statistical analysis, Student's t test was used.

\section{BrdU Proliferation Assay}

Undifferentiated cells cultivated on chamber slides were incubated with BrdU labeling solution (BRDU Kit; Roche, Mannheim, Germany) for $1 \mathrm{~h}$ at $37^{\circ} \mathrm{C}$ and $5 \% \mathrm{CO}_{2}$. After rinsing three times with the kit's washing solution, the specimens were incubated for $30 \mathrm{~min}$ at $37^{\circ} \mathrm{C}$ with BrdU antibody diluted 1:20 in incubation buffer. Slides were washed three times with washing solution and then incubated another $30 \mathrm{~min}$ with FITC-labeled anti-mouse IgG diluted 1:20 in PBS. Specimens were embedded in Vectashield mounting medium (Vector, Burlingame, Calif., USA) and analyzed with the fluorescence microscope Axioplan 2 (Zeiss, Jena, Germany). Examined field-of-view number $=10$; approximately 100 cells per field of view were analyzed.

Detection of Gene Expression by Quantitative Real-Time PCR

Undifferentiated cells or EBs collected at different time points after plating were washed twice with PBS and total RNA was isolated using the NucleoSpin RNA II Kit (Machery-Nagel, Düren, Germany). The RNA concentrations were determined by measuring the absorbance at $260 \mathrm{~nm}$. Samples of $500 \mathrm{ng}$ of RNA were reverse transcribed using the RevertAid ${ }^{\mathrm{TM}} \mathrm{H}$ Minus First Strand cDNA Synthesis Kit following the manufacturer's recommendations (Fermentas, St. Leon, Germany). Aliquots of $1 \mu$ from the RT reactions were mixed with $19 \mu \mathrm{l}$ master mix consisting of $0.4 \mu \mathrm{l}$ TaqMan probe, $0.4 \mu$ l gene-specific primer, $10 \mu \mathrm{l}$ iQ Supermix (Bio-Rad, Munich, Germany), and $7.8 \mu$ l sterile, steam-sterilized, and DEPC-treated water (Roth, Karlsruhe, Germany) per probe. The thermal cycling was done using an iCycler iQ thermal cycler running with software version 3.1 (Bio-Rad) according to the manufacturer's instructions and in the following thermal conditions: 


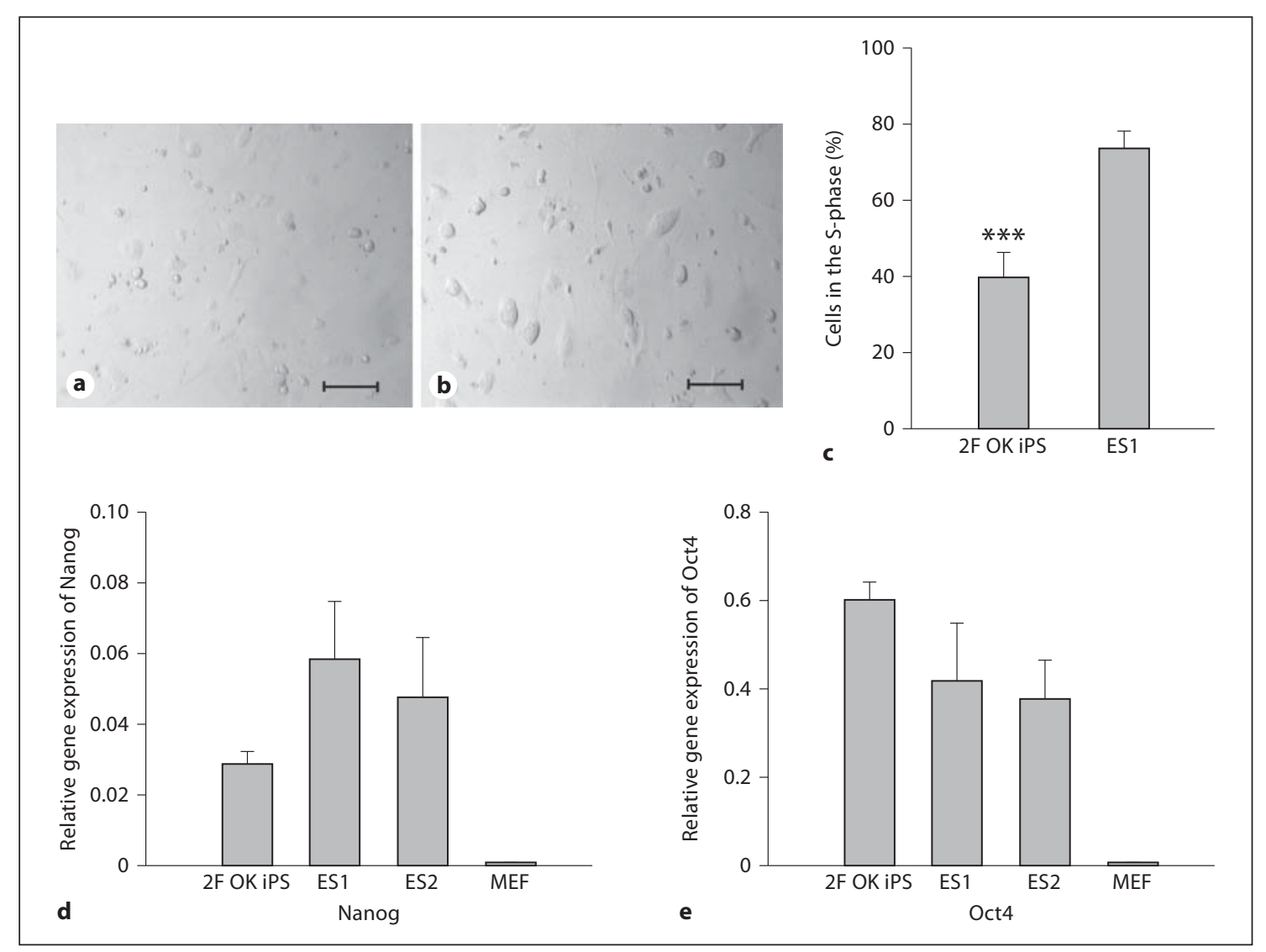

Fig. 1. $2 \mathrm{~F}$ OK iPS cells, clone F-4 (2F OK iPS), proliferate slower than D3 ES cells (ES1) and show some subtle differences in the expression level of pluripotency marker genes. Undifferentiated 2F OK iPS (a) and ES1 cells (b) at day 1 of cultivation. Quantification of BrdU proliferation assay to characterize the growth properties of $2 \mathrm{~F}$ OK iPS and ES1 cells (c). Mean values \pm SEM are shown. Significant differences (in comparison to ES1): ${ }^{* *} \mathrm{p} \leq$
0.001. Quantification of Nanog (d) and Oct4 (e) expression levels in undifferentiated iPS cells of line $2 \mathrm{~F} \mathrm{OK}$, clone F-4 (2F OK iPS), D3 ES cells (ES1) and EB5 NERT ES cells (ES2) by real-time PCR. MEF were used as a negative control. Mean values \pm SEM of normalized Nanog and Oct4 expression from examination of three RNA samples are shown. Scale bars $=200 \mu \mathrm{m}$.

For generation of standard curves, the PCR product was cloned into the vector pCR-TOPO (Invitrogen). Plasmid DNA was isolated using QIAGEN-tip 100 anion-exchange columns (Qiagen, Hilden, Germany) and serially diluted in double-distilled water. Threshold cycles were adjusted to attain the highest possible correlation coefficient value for the standard curve provided by the manufacturer's software. According to their respective cycle numbers the concentrations of unknown samples were deduced from the standard curve. Gene expression was determined relative to the expression of the house-keeping gene Gapdh.

\section{Immunostaining}

EBs cultivated on chamber slides were rinsed twice with PBS, fixed with methanol:acetone $(7: 10)$ for $5 \mathrm{~min}$ at $-20^{\circ} \mathrm{C}$, washed three times with PBS again and incubated with $7.5 \%$ bovine serum albumin (BSA) for $30 \mathrm{~min}$ at room temperature. Specimens were then incubated with the primary antibodies in a humidified chamber for $1 \mathrm{~h}$ at $37^{\circ} \mathrm{C}$. Immunostaining was performed using 


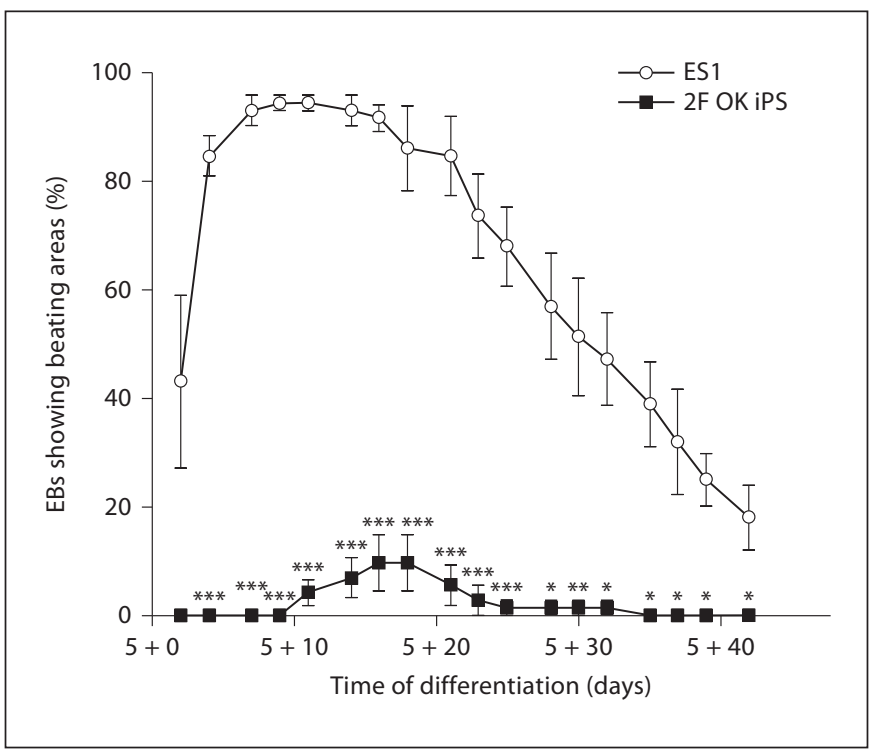

Fig. 2. Development of beating areas in EBs during differentiation of iPS cells of line 2F OK, clone F-4 (2F OK iPS), and D3 ES cells (ES1). Mean values \pm SEM from independent experiments $(\mathrm{n}=$ 3) are shown. Significant differences (in comparison to ES1 cells): ${ }^{*} \mathrm{p} \leq 0.05 ;{ }^{* *} \mathrm{p} \leq 0.01 ;{ }^{* *} \mathrm{p} \leq 0.001$.

a monoclonal antibody against collagen type II (II-II6B3; Developmental Studies Hybridoma Bank, Iowa City, Iowa, USA) diluted 1:50 in PBS. After rinsing four times with PBS, slides were incubated for $1 \mathrm{~h}$ at $37^{\circ} \mathrm{C}$ with FITC-labeled anti-mouse IgG (Dianova, Hamburg, Germany), diluted 1:200. Slides were washed four times in PBS and one time in distilled water. Specimens were embedded in Vectashield mounting medium (Vector) and analyzed with the fluorescence microscope Axioplan 2 (Zeiss) and the confocal laser scanning microscope LSM510 Meta (Zeiss).

\section{Results}

Undifferentiated iPS Cells of Line 2F OK Show Subtle Differences Compared to ES Cells

Growing on mitotically inactivated MEF undifferentiated murine iPS cells of line $2 \mathrm{~F}$ OK, clone F-4, (2F OK iPS) formed colonies very similar to ES cells of line D3 (ES1) but smaller in size (fig. 1a, b) indicating that they proliferate slower. To confirm this finding, a BrdU proliferation assay was performed. Examination of the proliferation rate of $2 \mathrm{~F}$ OK iPS cells with ES1 cells demonstrated that the analyzed ES cell line proliferated approximately 1.9-fold faster than the iPS cells (fig. 1c). At the time of assessment, $40 \%$ of the iPS cells had entered the S-phase of the cell cycle, in contrast to $74 \%$ in the case of the ES cells (fig. 1c).
Histochemical analysis showed that 2F OK iPS cells expressed alkaline phosphatase and, as demonstrated by immunostaining, stained positive for SSEA1, Nanog and Oct4 (data not shown). Some marker seemed to be expressed on slightly different levels in iPS cells in comparison to ES cells. In fact, quantitative real-time PCR analysis of the expression of pluripotency-associated genes revealed at least some differences between undifferentiated murine 2F OK iPS and ES cells. Two murine ES cell lines, the line D3 (ES1) and the line EB5 NERT (ES2), were analyzed in comparison to $2 \mathrm{~F}$ OK iPS cells. Both ES cell lines showed comparable expression levels of Nanog and Oct4 (fig. 1d, e). 2F OK iPS cells expressed approximately 1.8fold lower levels of Nanog and about 1.5-fold higher levels of Oct4 compared to both ES cell lines although the differences were not statistically significant (fig. 1d, e). The higher expression level of Oct4 should not be related to exogenous vector-driven Oct4 expression [Kim et al., 2008]. These subtle differences observed between the analyzed iPS and ES cells may be due to clonal variation.

\section{Cardiogenic Differentiation of $2 \mathrm{~F}$ OK iPS Cells}

The analyzed 2F OK iPS and ES1 cells both formed EBs although the iPS cell-derived EBs were more compact with fewer outgrowing cells in comparison to ES cell-derived EBs (data not shown). As a simple and wellestablished test for mesodermal differentiation, we initially screened 2F OK iPS and ES1 cell-derived EBs for the formation of beating clusters of cardiac cells. From 2 days after plating of EBs (5 + 2 days) until day 42 of differentiation ( $5+42$ days), plated EBs were examined. The first contracting iPS cell-derived EBs were detected 11 days after plating $(5+11$ days), whereas the first beating ES cell-derived EBs could already be observed at day 2 of differentiation (fig. 2). During further cultivation the amount of beating iPS and ES cell-derived EBs increased up to 16 days after plating. Throughout differentiation, 2F OK iPS cells showed less efficient cardiogenesis compared to ES1 cells. At $5+16$ days, ES cell-derived EBs showed approximately 10 -fold higher cardiogenic differentiation compared to iPS cells.

\section{F OK iPS Cells Differentiate into Chondrocytes in vitro}

The first signs of chondrogenesis appeared in the form of Alcian blue-stained nodules in the outgrowths of $2 \mathrm{~F}$ OK iPS cell-derived EBs indicating the production of acidic proteoglycans which are characteristic of cartilage tissue. The first Alcian blue-positive nodules were detected 14 days after plating of EBs $(5+14$ days), 7 days later 
Fig. 3. Formation of Alcian blue-positive cartilage nodules. The number of Alcian blue-stained nodules increased during early differentiation of both iPS cells of line $2 \mathrm{~F} \mathrm{OK}$, clone F-4 (2F OK iPS), and D3 ES cells (ES1) (a). Mean values \pm SEM from independent experiments $(n=3)$ are shown. Alcian blue staining demonstrating differentiation of chondrogenic cells in the outgrowths of EBs at $5+42$ days $(\mathbf{b}, \mathbf{c})$. The $2 \mathrm{~F}$ OK iPS cell-derived nodule (b) showed the same size and intensity of Alcian blue staining as the ES1 cell-derived one (c). Representative pictures are shown. Scale bars $=200 \mu \mathrm{m}$.

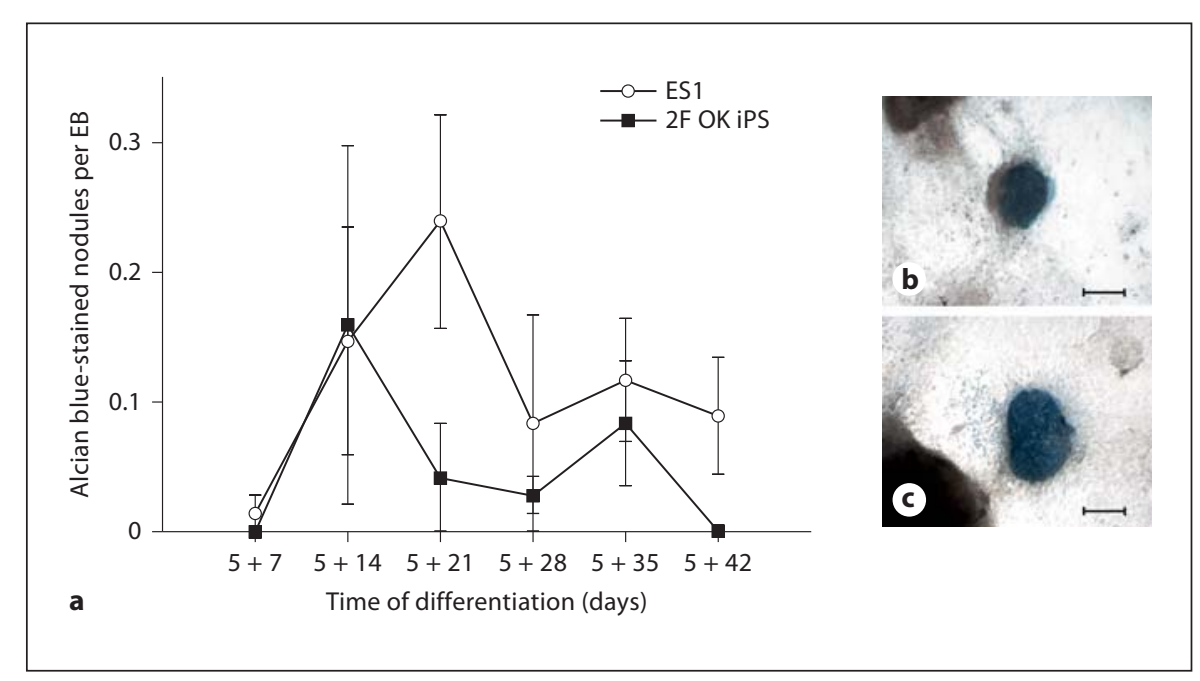

when the first nodules appeared in ES1 cell-derived EBs $(5+7$ days) (fig. 3a). Nodules developing in the outgrowths of 2F OK iPS cell-derived EBs showed the same size and morphology and intensity of Alcian blue staining as those derived from the ES1 cells (fig. 3b, c). During further EB cultivation, the number of iPS cell-derived nodules decreased, whereas the number of ES cell-derived nodules increased up to 21 days after plating. Later, the number of Alcian blue-positive nodules decreased in both iPS and ES cell-derived EBs (fig. 3a). Overall, the differences observed in the efficiency of chondrogenic nodule differentiation were not statistically significantly different between the analyzed ES and iPS cells.

The formation of Alcian blue-stained nodules in the outgrowths of EBs was accompanied by expression of the cartilage marker molecule collagen type II. Quantitative real-time PCR analysis revealed that the expression level of collagen type II increased continually in $2 \mathrm{~F}$ OK iPS cell-derived EBs up to 14 days after plating $(5+14$ days) and up to 7 days after plating ( $5+7$ days) in ES1 cell-derived EBs (fig. 4a). During further differentiation, $2 \mathrm{~F} \mathrm{OK}$ iPS cell-derived EBs expressed somewhat higher levels of collagen type II compared to ES1 cell-derived EBs.

Expression of collagen type II was further demonstrated by immunostaining (fig. 4b, c). Again, concerning nodule size, morphology, and fluorescence intensity no differences could be observed between 2F OK iPS and ES1 cell-derived collagen type II-positive nodules. Confocal microscopy demonstrated the highly organized three-dimensional structure of a $2 \mathrm{~F}$ OK iPS cell-derived cartilage nodule consisting of round-shaped cells surrounded by extracellular matrix (fig. $4 \mathrm{~d}$, e). These find- ings are in accordance with the results of confocal microscopy of ES cell-derived nodules of line D3 [Kramer et al., 2005b].

Chondrogenesis Is Enhanced by Growth Factors of the TGF- $\beta$ Family during Differentiation of $2 F$ OK $i P S$ Cells

Treatment of 2F OK iPS cell-derived EBs with $10 \mathrm{ng} /$ $\mathrm{ml}$ BMP-2 during the suspension phase (2-5 days) resulted in a slight increase in Alcian blue-stained nodules (fig. 5a). The enhancing effect was first discovered 2 weeks after plating $(5+14$ days) and was confirmed by quantitative real-time PCR analysis (fig. 5b). Throughout differentiation, BMP-2-treated 2F OK iPS cell-derived EBs showed remarkably higher collagen type II expression compared to untreated EBs, especially during early EB cultivation from $5+11$ to $5+18$ days. At $5+14$ days, BMP-2-treated 2F OK iPS cell-derived EBs expressed about 2.6-fold higher levels of collagen type II than the control EBs.

Treatment of 2F OK iPS cell-derived EBs with $10 \mathrm{ng} /$ $\mathrm{ml} \mathrm{BMP}-2$ and $2 \mathrm{ng} / \mathrm{ml}$ TGF- $\beta_{1}$ during the suspension phase (2-5 days) resulted in an even higher and statistically significant increase in Alcian blue-positive nodules (fig. 5a). At $5+35$ days, these EBs showed an approximately 3.6-fold higher number of Alcian blue-stained nodules compared to the untreated variant. However, the induction of chondrogenesis by simultaneous application of BMP- 2 and TGF- $\beta_{1}$ could not be confirmed by realtime PCR analysis. Throughout differentiation, doubletreated EBs showed no significantly higher expression of collagen type II than untreated EBs (fig. 5b). 


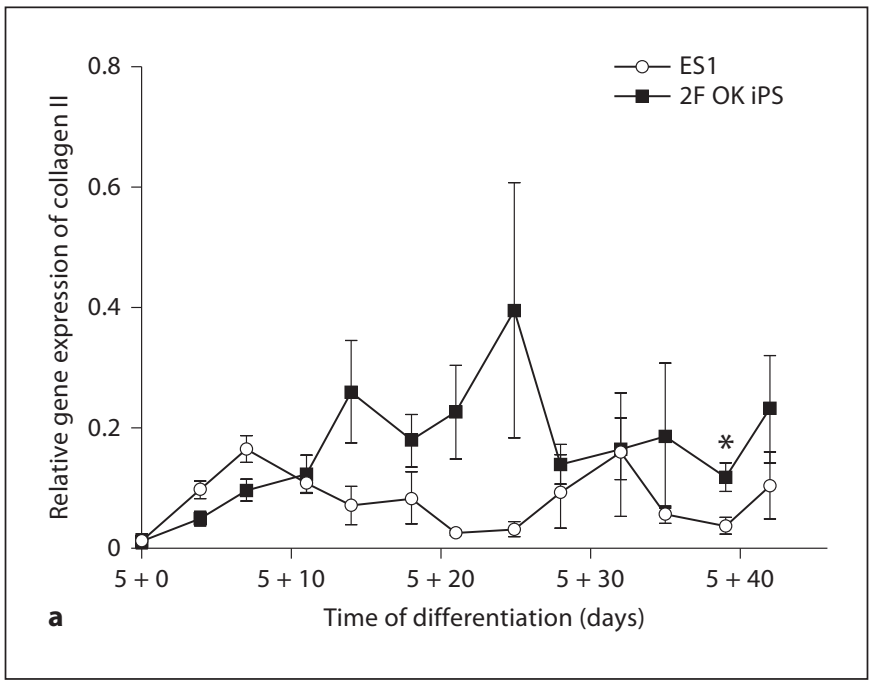

Fig. 4. Expression of collagen type II during differentiation of iPS cells of line 2F OK, clone F-4 (2F OK iPS), and D3 ES cells (ES1). Collagen type II was expressed with a somewhat higher level in the case of $2 \mathrm{~F}$ OK iPS cells (a). Mean values \pm SEM from independent experiments $(n=3)$ are shown. Significant differences (in comparison to ES1): ${ }^{*} \mathrm{p} \leq 0.05$. Collagen type II-positive nodules in the outgrowths of $2 \mathrm{~F} \mathrm{OK} \mathrm{iPS} \mathrm{cell-derived} \mathrm{EBs} \mathrm{at} 5+35$ days (b)

\section{Discussion}

\section{The Analyzed iPS Cell Line 2F OK Shows Subtle}

Differences Compared to D3 ES Cells

We showed that the proliferation rate of murine $2 \mathrm{~F} \mathrm{OK}$ iPS cells, clone F-4, is somewhat lower than that of ES cells of line D3 (ES1). Further, we demonstrated that some subtle differences exist between the analyzed 2F OK iPS and ES1 cells in the gene expression levels of the pluripotency markers Nanog and Oct4. Various iPS cell lines generated from different cell types in fact show remarkable differences with respect to pluripotency marker expression [Kaichi et al., 2010; Kim et al., 2010a]. In general, differences among iPS cells and between ES and iPS cells have been reported which are most probably caused by epigenetic marks of the cell type of origin [Kim et al., 2010b; Polo et al., 2010; Ohi et al., 2011]. Evidence has further been presented that external stimuli have a profound influence on the reprogramming process [Polo et al., 2010; Orlando et al., 2012] which can result in adaption to the culture conditions [Polo et al., 2010]. The number and combination of reprogramming factors, on the other hand, does not seem to influence the pluripotency properties very much. For example, Kim et al. [2008] showed that $2 \mathrm{~F}$ iPS cells exhibit pluripotency marker expression

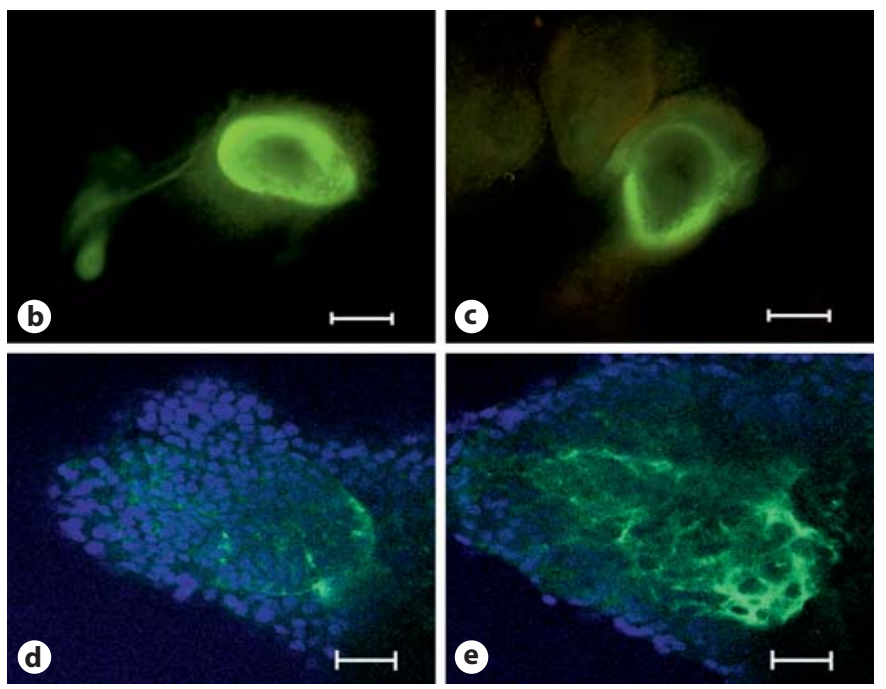

showed the same size and fluorescence intensity as those from ES1 cell-derived EBs (c). Confocal microscopy of a nodule derived from $2 \mathrm{~F}$ OK iPS cells at $5+28$ days $(\mathbf{d}, \mathbf{e})$. Confocal sections of 1.45 $\mu \mathrm{m}$, immunostained for collagen type II and DAPI, demonstrate its highly organized three-dimensional structure. Representative pictures are shown. Scale bars $=100 \mu \mathrm{m}$.

patterns similar to those of four-factor iPS cells. 2F iPS cells were found to be highly similar to both four-factor iPS cells and murine ES cells at the global transcription level [Kim et al., 2008]. Similarly, the differences observed in this study between $2 \mathrm{~F}$ OK iPS cells and ES cells are rather small and reflect normal clonal variation.

\section{The Chondrogenic Differentiation Potential of $2 \mathrm{~F} \mathrm{OK}$} iPS Cells Is Similar to that of D3 ES Cells

Heretofore, numerous studies have demonstrated that murine iPS cells can be differentiated into various cell types using the same protocols used for ES cells but often less efficiently compared to ES cells (e.g. Kuzmenkin et al. [2009], Pfannkuche et al. [2009], Tashiro et al. [2009], and Hu et al. [2010]). For example, some iPS cells showed less efficient adipocyte differentiation compared to ES cells [Tashiro et al., 2009]. However, other differentiation directions such as osteoblast differentiation were equally efficient for iPS and ES cells [Tashiro et al., 2009].

Our data demonstrate that murine 2F OK iPS cells cultivated via EBs possess the capability to differentiate spontaneously into chondrogenic cells in vitro. This was shown by the appearance of Alcian blue-stained nodules and the expression of the cartilage marker molecule collagen type II. 2F OK iPS cell-derived chondrogenic nod- 


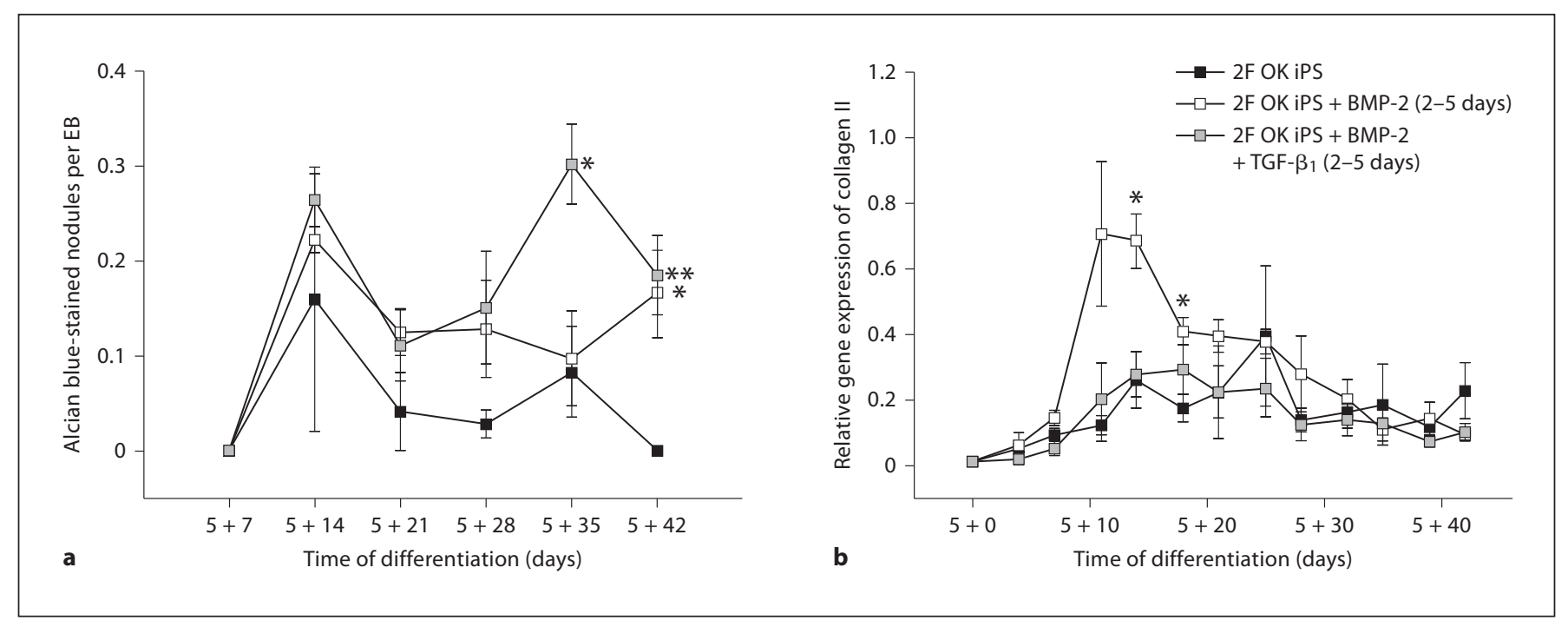

Fig. 5. Growth factors of the TGF- $\beta$ family induce chondrogenesis in cells of line 2F OK, clone F-4 (2F OK iPS). Application of BMP-2 (10 ng/ml) during suspension (2-5 days) resulted in a slight increase in the number of Alcian blue-stained nodules (a). Application of BMP-2 $(10 \mathrm{ng} / \mathrm{ml})$ in combination/with TGF- $\beta_{1}$ (2 $\mathrm{ng} / \mathrm{ml})$ led to an even stronger enhancement (a). BMP-2-appli- cation resulted in an upregulation of collagen type II expression, in particular during early differentiation, whereas simultaneous treatment with both BMP-2 and TGF- $\beta_{1}$ showed no effect on gene expression (b). Mean values \pm SEM from independent experiments $(n=3)$ are shown. Significant differences (in comparison to the untreated control): ${ }^{*} \mathrm{p} \leq 0.05 ;{ }^{* *} \mathrm{p} \leq 0.01$. ules were shown to be equivalent to nodules of ES cells of line D3 (ES1) regarding their size and morphology as well as the intensity of Alcian blue staining and fluorescence for collagen type II expression. Throughout $2 \mathrm{~F}$ OK iPS cell differentiation, the number of Alcian bluestained nodules was somewhat lower than in ES1 cells, but the differences were not statistically significant. In line with this, the analysis of collagen type II gene expression revealed no significant difference between both cell lines. In conclusion, we thus believe that the iPS cells are able to be used as a good alternative system to ES cells for the analysis of chondrogenic cell differentiation.

However, with ES1 cells as a control, we found that throughout differentiation 2F OK iPS cell-derived EBs formed beating areas at a significantly less efficient rate compared to ES1 cells. These results suggest that $2 \mathrm{~F} \mathrm{OK}$ iPS cells differentiate less efficiently in this direction compared to ES1 cells. Other studies confirmed that iPS cell-derived cardiac differentiation was significantly delayed compared to ES cells [Kuzmenkin et al., 2009] and showed that an optimized differentiation protocol was needed to achieve efficient iPS cell cardiogenesis [Pfannkuche et al., 2009].
As mentioned above, iPS cells retain an epigenetic memory of their tissue of origin that might hinder or even limit their differentiation propensity, favoring differentiation along lineages not related to the donor cell type [Kim et al., 2010b; Polo et al., 2010; Ohi et al., 2011]. The kind and combination of reprogramming factors, on the other hand, does not seem to influence the pluripotency properties very much since it has been shown that differences between ES and iPS cells regarding their in vitro differentiation potential do not depend on the kind and number of factors used for reprogramming [Hu et al., 2010; Kaichi et al., 2010]. 2F OK iPS cells are derived from neural stem cells [Kim et al., 2008] and might therefore prefer to differentiate into the ectodermal differentiation lineage. At least some chondrocytes differentiating in ES cell-derived EBs might be of ectodermal neural crest cell origin [Haller et al., 2012] in contrast to cardiac cells which are mesoderm derived. Furthermore, it has been published previously that differences in differentiation efficiencies also exist among several murine [Kramer et al., 2005a] and human [Osafune et al., 2008] ES cell lines. Although an explanation for this phenomenon is still missing, one might speculate that it could also have been brought about by genetic or epigenetic differences among the different cell clones [Fenno et al., 2008]. 
Growth Factors of the TGF- $\beta$ Family Enhance Chondrogenic Differentiation of iPS Cells of Line $2 \mathrm{~F} \mathrm{OK}$

The growth factors BMP-2 and TGF- $\beta_{1}$ were applied to EBs derived from $2 \mathrm{~F}$ OK iPS cells, clone F-4, in a concentration that has been shown to be able to induce chondrogenic differentiation of murine D3 ES cells [Kramer et al., 2000; zur Nieden et al., 2005]. Previously, it has been demonstrated that TGF- $\beta_{1}$ treatment of D3 ES cell-derived EBs results in a decreased number of Alcian bluestained areas per EB, whereas BMP-2-treatment during the suspension phase of EBs (2-5 days) results in enhanced chondrogenesis [Kramer et al., 2000]. It has also been shown that simultaneous treatment with BMP-2 and TGF- $\beta_{1}$ during the suspension culture of ES cell-derived EBs and subsequent application of ascorbic acid, insulin, and BMP-2 leads to a significantly higher gene expression of several cartilage markers [zur Nieden et al., 2005]. Our data show that BMP-2 treatment resulted in enhanced collagen type II expression in 2F OK iPS cellderived EBs while the formation of cartilage nodules was not significantly enhanced. Collagen type II is already expressed in ES-derived precartilage condensations prior to nodule formation [Kramer et al., 2000; Hargus et al., 2008]. Enhanced collagen type II expression during early stages of EB differentiation could therefore be brought about by an induction of precartilage condensations to such an extent that the rise in collagen type II mRNA can be measured by RT-PCR. If these condensations do not maturate further they do not necessarily influence the outcome of cartilage nodule number. We might thus speculate that BMP-2 represents an early inducer of chondrogenesis, possibly forcing the formation of precartilage condensations. Simultaneous treatment with BMP-2 and TGF- $\beta_{1}$, on the other hand, showed an enhancing effect on the number of Alcian blue-stained nodules but no significant modulation of cartilage-associated gene expression. Induction of cartilage nodule number in this case may only result in a measureable increase in collagen type II expression if enough nodules are present. Since the efficiency of differentiation of mature nodules is rather low in general, these differences could have escaped detection.

\section{Acknowledgements}

The authors thank Hans Schöler and Holm Zaehres (Max Planck Institute for Molecular Biomedicine, Münster, Germany) for the 2F OK iPS cell clone F-4, and Ursula Just (Institute of Biochemistry, Christian-Albrechts-Universität of Kiel, Kiel, Germany) for the ES cell line EB5 NERT. The II-II 6B3 monoclonal antibody developed by T.F. Linsenmayer was obtained from the Developmental Studies Hybridoma Bank developed under the auspices of the NICHD and maintained by the University of Iowa, Department of Biological Sciences, Iowa City, Iowa, USA. The skillful technical assistance of A. Tiedtke, B. Andresen, and $\mathrm{H}$. Steenbock is gratefully acknowledged. This work was supported by funding from Intermed Service GmbH (Geesthacht, Germany) to J.K. and J.R. and by the Stiftung Osteogenesis Imperfecta Betroffene (OI-Stiftung, Stuttgart, Germany) to J.K.

\section{References}

Doetschman, T.C., H. Eistetter, M. Katz, W. Schmidt, R. Kemler (1985) The in vitro development of blastocyst-derived embryonic stem cell lines: formation of visceral yolk sac, blood islands and myocardium. J Embryol Exp Morphol 87: 27-45.

Evans, M.J., M.H. Kaufman (1981) Establishment in culture of pluripotential cells from mouse embryos. Nature 292: 154-156.

Fenno, L.E., L.M. Ptaszek, C.A. Cowan (2008) Human embryonic stem cells: emerging technologies and practical applications. Curr Opin Genet Dev 18: 324-329.

Haller, R., R. Schwanbeck, S. Martini, K. Bernoth, J. Kramer, U. Just, J. Rohwedel (2012) Notch1 signaling regulates chondrogenic lineage determination through Sox9 activation. Cell Death Differ 19: 461-469.

-Hargus, G., R. Kist, J. Kramer, D. Gerstel, A. Neitz, G. Scherer, J. Rohwedel (2008) Loss of Sox 9 function results in defective chon- drocyte differentiation of mouse embryonic stem cells in vitro. Int J Dev Biol 52: 323 332.

Hegert, C., J. Kramer, G. Hargus, J. Müller, K. Guan, A.M. Wobus, P.K. Müller, J. Rohwedel (2002) Differentiation plasticity of chondrocytes derived from mouse embryonic stem cells. J Cell Sci 115: 4617-4628.

Hu, B.Y., J.P. Weick, J. Yu, L.X. Ma, X.Q. Zhang, J.A. Thomson, S.C. Zhang (2010) Neural differentiation of human induced pluripotent stem cells follows developmental principles but with variable potency. Proc Natl Acad Sci USA 107: 4335-4340.

Kaichi, S., K. Hasegawa, T. Takaya, N. Yokoo, T. Mima, T. Kawamura, T. Morimoto, K. Ono, S. Baba, H. Doi, S. Yamanaka, T. Nakahata, T. Heike (2010) Cell line-dependent differentiation of induced pluripotent stem cells into cardiomyocytes in mice. Cardiovasc Res 88 : 314-323.

\footnotetext{
Kang, L., J. Wang, Y. Zhang, Z. Kou, S. Gao (2009) iPS cells can support full-term development of tetraploid blastocyst-complemented embryos. Cell Stem Cell 5: 135138.

Kim, K., A. Doi, B. Wen, K. Ng, R. Zhao, P. Cahan, J. Kim, M.J. Aryee, H. Ji, L.I. Ehrlich, A. Yabuuchi, A. Takeuchi, K.C. Cunniff, H. Hongguang, S. McKinney-Freeman, O. Naveiras, T.J. Yoon, R.A. Irizarry, N. Jung, J. Seita, J. Hanna, P. Murakami, R. Jaenisch, R. Weissleder, S.H. Orkin, I.L. Weissman, A.P. Feinberg, G.Q. Daley (2010b) Epigenetic memory in induced pluripotent stem cells. Nature 467: 285-290.

Kim, E.Y., K. Jeon, H.Y. Park, Y.J. Han, B.C. Yang, S.B. Park, H.M. Chung, S.P. Park (2010a) Differences between cellular and molecular profiles of induced pluripotent stem cells generated from mouse embryonic fibroblasts. Cell Reprogram 12: 627-639.
} 
Kim, J.B., H. Zaehres, G. Wu, L. Gentile, K. Ko, V. Sebastiano, M.J. Arauzo-Bravo, D. Ruau, D.W. Han, M. Zenke, H.R. Schöler (2008) Pluripotent stem cells induced from adult neural stem cells by reprogramming with two factors. Nature 454: 646-650.

Kramer, J., C. Hegert, K. Guan, A.M. Wobus, P.K. Muller, J. Rohwedel (2000) Embryonic stem cell-derived chondrogenic differentiation in vitro: activation by BMP-2 and BMP4. Mech Dev 92: 193-205.

-Kramer, J., C. Hegert, G. Hargus, J. Rohwedel (2005a) Mouse ES cell lines show a variable degree of chondrogenic differentiation in vitro. Cell Biol Int 29: 139-146.

Kramer, J., M. Klinger, C. Kruse, M. Faza, G. Hargus, J. Rohwedel (2005b) Ultrastructural analysis of mouse embryonic stem cell-derived chondrocytes. Anat Embryol (Berl) 210: 175-185.

Kuzmenkin, A., H. Liang, G. Xu, K. Pfannkuche, H. Eichhorn, A. Fatima, H. Luo, T. Saric, M. Wernig, R. Jaenisch, J. Hescheler (2009) Functional characterization of cardiomyocytes derived from murine induced pluripotent stem cells in vitro. FASEB J 23: 41684180.

Maherali, N., K. Hochedlinger (2008) Guidelines and techniques for the generation of induced pluripotent stem cells. Cell Stem Cell 3: 595-605.

Ohi, Y., H. Qin, C. Hong, L. Blouin, J.M. Polo, T. Guo, Z. Qi, S.L. Downey, P.D. Manos, D.J. Rossi, J. Yu, M. Hebrok, K. Hochedlinger, J.F. Costello, J.S. Song, M. Ramalho-Santos (2011) Incomplete DNA methylation underlies a transcriptional memory of somatic cells in human iPS cells. Nat Cell Biol 13: 541-549.
Okita, K., T. Ichisaka, S. Yamanaka (2007) Generation of germline-competent induced pluripotent stem cells. Nature 448: 313-317.

-Orlando, L., Y. Sanchez-Ripoll, J. Foster, H. Bone, C. Giachino, M.J. Welham (2012) Differential coupling of self-renewal signaling pathways in murine induced pluripotent stem cells. PLoS One 7: e30234.

Osafune, K., L. Caron, M. Borowiak, R.J. Martinez, C.S. Fitz-Gerald, Y. Sato, C.A. Cowan, K.R. Chien, D.A. Melton (2008) Marked differences in differentiation propensity among human embryonic stem cell lines. Nat Biotechnol 26: 313-315.

- Pfannkuche, K., H. Liang, T. Hannes, J. Xi, A. Fatima, F. Nguemo, M. Matzkies, M. Wernig, R. Jaenisch, F. Pillekamp, M. Halbach, H. Schunkert, T. Saric, J. Hescheler, M. Reppel (2009) Cardiac myocytes derived from murine reprogrammed fibroblasts: intact hormonal regulation, cardiac ion channel expression and development of contractility. Cell Physiol Biochem 24: 73-86.

Polo, J.M., S. Liu, M.E. Figueroa, W. Kulalert, S. Eminli, K.Y. Tan, E. Apostolou, M. Stadtfeld, Y. Li, T. Shioda, S. Natesan, A.J. Wagers, A. Melnick, T. Evans, K. Hochedlinger (2010) Cell type of origin influences the molecular and functional properties of mouse induced pluripotent stem cells. Nat Biotechnol 28: 848-855.

Rohwedel, J., V. Maltsev, E. Bober, H.H. Arnold, J. Hescheler, A.M. Wobus (1994) Muscle cell differentiation of embryonic stem cells reflects myogenesis in vivo: developmentally regulated expression of myogenic determination genes and functional expression of ionic currents. Dev Biol 164: 87-101.
Schroeder, T., F. Meier-Stiegen, R. Schwanbeck, H. Eilken, S. Nishikawa, R. Hasler, S. Schreiber, G.W. Bornkamm, U. Just (2006) Activated Notch1 alters differentiation of embryonic stem cells into mesodermal cell lineages at multiple stages of development. Mech Dev 123: 570-579.

- Takahashi, K., S. Yamanaka (2006) Induction of pluripotent stem cells from mouse embryonic and adult fibroblast cultures by defined factors. Cell 126: 663-676.

- Tashiro, K., M. Inamura, K. Kawabata, F. Sakurai, K. Yamanishi, T. Hayakawa, H. Mizuguchi (2009) Efficient adipocyte and osteoblast differentiation from mouse induced pluripotent stem cells by adenoviral transduction. Stem Cells 27: 1802-1811.

Wernig, M., A. Meissner, R. Foreman, T. Brambrink, M. Ku, K. Hochedlinger, B.E. Bernstein, R. Jaenisch (2007) In vitro reprogramming of fibroblasts into a pluripotent EScell-like state. Nature 448: 318-324.

Wobus, A.M., R. Grosse, J. Schöneich (1988) Specific effects of nerve growth factor on the differentiation pattern of mouse embryonic stem cells in vitro. Biomed Biochim Acta 47: 965-973.

Wobus, A.M., G. Wallukat, J. Hescheler (1991) Pluripotent mouse embryonic stem cells are able to differentiate into cardiomyocytes expressing chronotropic responses to adrenergic and cholinergic agents and $\mathrm{Ca}^{2+}$ channel blockers. Differentiation 48: 173-182.

zur Nieden, N.I., G. Kempka, D.E. Rancourt, H.J. Ahr (2005) Induction of chondro-, osteoand adipogenesis in embryonic stem cells by bone morphogenetic protein-2: effect of cofactors on differentiating lineages. BMC Dev Biol 5: 1. 